\title{
Use of Primer Design to Detect the Glycoprotein C Gene of Canine Herpes Virus by Polymerase Chain Reaction
}

\author{
Marco Vargas, María Antonieta Jara and Carlos Navarro* \\ Department of Medicina Preventiva Animal, Universidad de Chile, Chile \\ *Corresponding Author: Carlos Navarro, Department of Medicina \\ Preventiva Animal, Universidad de Chile, Chile.
}

DOI: $10.31080 /$ ASVS.2022.04.0337
Received: February 04, 2022

Published: February 23, 2022

(C) All rights are reserved by Carlos Navarro., et al.

\begin{abstract}
The fundamental difference between a virus and microorganisms lies in the way they generate progeny and some viruses destroy the cell membrane, a phenomenon called cytolysis. The herpes virus has this cytolytic capacity and in veterinary medicine, several important herpes viruses have been described, among which is the Canine Herpes Virus type 1 (CaHV-1) and this study contributed both to the genomic characterization of a national isolate of the CaHV-1 virus -called RP5- as well as to small animal veterinary medicine with a specific, sensitive, and fast diagnostic method result. For this, detection of the CaHV-1 glycoprotein C gene was performed by Polymerase Chain Reaction using a pair of primers designed in silico. Using a temperature gradient thermocycler, the alignment temperature $\left(55^{\circ} \mathrm{C}\right)$ was established by the clear and unequivocal observation of a DNA fragment of approximately $200 \mathrm{bp}$. These fragments were sequenced and a percentage of nucleotide identity (NIP > 94\%) was established with respect to the official GenBank data and indicates that the amplified fragment corresponds to the gC gene fragment of CaHV-1. Thus, this methodology constitutes another technique of choice for the detection of CaHV-1 in Small Animal Medicine.
\end{abstract}

Keywords: Canine Herpes Virus; Glycoprotein C; Diagnosis; In Silico

\section{Introduction}

Canine herpes virus type 1 (CaHV-1) belongs to the order Herpesvirales, family Herpesviridae, subfamily Alphaherpesvirinae, genus Varicellovirus [1] Most of the herpesviruses of veterinary importance belong to the genus Varicellovirus [2]. Within the Herpesviridae family there are four subfamilies: Alphaherpesvirinae, Betaherpesvirinae, Gammaherpesvirinae and a fourth yet unnamed [1]. This definition of groups is based on biological characteristics and molecular determinations such as: nucleotide sequencing or phylogenetic analysis $[3,4]$.

The members of the Herpesviridae family present their genome as a linear double-stranded DNA molecule, whose size is between 125 and 235 thousand base pairs (bp). They have a capsid of icosahedral symmetry with a size of $125 \mathrm{~nm}$ that surrounds this double strand and which, in turn, is surrounded by the integument, which corresponds to an amorphous layer of fibrous protein structure. All these structures are covered by a lipid envelope, whose surface is not regular, since it has projections that are evenly distributed. Finally, the size of the viral particle varies between 120 and $300 \mathrm{~nm}$ $[2,5,6]$.

The Alphaherpesvirinae subfamily has a wide range of hosts which it infects by carrying out lytic cycles in the cells and producing a state of latent infection, remaining inactive mainly in the sensory ganglia [7], being able to restart its propagation in stress events $[4,5]$.

\section{Viral replication}

In the cell, five stages are distinguished, which in chronological order are: adsorption, penetration, nucleic acid and protein synthesis, assembly and finally release, which leads to cell lysis. Once inside the cell, the virus stimulates the cell to synthesize the elements necessary for its replication $[3,5]$. The cells susceptible to being infected are determined by the interaction, in the adsorption, between the receptors present in the cells and viral proteins, which has a high specificity. However, even when the virus has penetrated 
the cell, this does not guarantee viral multiplication, since the copies of the viral genome have not yet been produced and therefore the specific proteins of the virus have not been synthesized $[5,8]$.

There are three mRNAs synthesized in the viral replication process: immediate early $(\alpha)$ that encodes regulatory proteins; the delayed early $(\beta)$ that encodes proteins that participate in DNA replication and the late $(\gamma)$ that encodes structural proteins of the viral particle. Early proteins and late proteins are synthesized from these mRNAs. The former is synthesized immediately after the infection and are necessary for the replication of viral nucleic acids; the late ones are synthesized later, among which are the glycoproteins of the virus envelope, such as glycoproteins B and C $[3,5,8]$.

\section{Glycoprotein C}

Glycoprotein C is encoded by the gC gene of CaHV-1 and from the point of view of the immune response it would have an important role, since it has been described as the receptor involved in the recognition of cells infected by herpes viruses by complement factors $[9,10]$. On the other hand, from the perspective of infection control, the use of a recombinant vaccine that expresses the $\mathrm{gB}, \mathrm{gC}$ and gD genes could be highly useful [11].

The gC gene is made up of $1380 \mathrm{bp}$ and its nucleotide sequence is available in official databases (Genbank AF361074.1). Thus, the establishment of a conventional PCR protocol to detect gC can be obtained using some bioinformatic tools such as the In silico design of primers, since its detection through this molecular technique -apparently- has not had the same diffusion as the information regarding the nucleotide sequences of several CaHV-1 genes $[10,12$ $14]$.

\section{Virus and associated disease}

There are dogs infected with herpes viruses all over the world, these are concentrated in canine communities, shelters, dog hotels, stables and especially in kennels, where the seroprevalence can exceed $90 \%$. In these places, half of the seropositive animals present reproductive disorders $[15,16]$.

An important characteristic for the control of this virus is its fragility, since its lipid glycoprotein envelope is easily destroyed by heat, ultraviolet light, lipid solvents and common disinfectants [3]. It is easily inactivated at temperatures above $40^{\circ} \mathrm{C}$, even though the optimal temperature for its replication and therefore cell lysis is between 32 and $33^{\circ} \mathrm{C}[15,16]$.
Viral transmission is carried out through contact between mucous membranes, therefore it requires close contact between an infected animal that is releasing the virus and a susceptible one, this occurs during intercourse, when they lick or when mothers caress their young. When many animals inhabit a small space, the most important way in which the virus passes from one individual to another is through short-distance respiratory aerosol spread [3].

In puppies there are two forms of presentation, one that is characterized by sudden death, called super-acute and an acute presentation, which is the most common, which initially presents as digestive disorders, anorexia, grayish liquid stools continuous vomiting and groaning due to abdominal pain; and that later evolves into nervous symptoms of encephalomyelitis followed by coma and death. The fulminant form is characterized by being of short duration and very severe, with $80 \%$ mortality in animals less than a week old, and the surviving infected puppies present irreversible cerebellar and articular sequelae. When the virus infects older puppies and adults, the clinical picture caused consists of other pathological signs, which manifest when the viral presence is accompanied by other factors, such as a bacterial infection and stress phenomena: eye and rhinopharyngeal conditions that manifest clinically as "kennel cough". In the case of females, it produces a mild vaginitis; When the gravid uterus is infected, miscarriages, calving problems, and infertility occur $[2,3,15]$.

\section{Diagnostic methods and their drawbacks}

Necropsy of infected puppies reveals petechiae in the liver, spleen, lungs, and kidneys. In these affected organs or in secretions, characteristic lesions can be verified at the histological level, such as intranuclear inclusion bodies, or the direct immunofluorescence technique can be used to detect the viral antigen. However, viral isolation in permissive cells is the gold standard or definitive diagnosis. Unfortunately, the above is achieved -in general- a month after the start of the study, for which it is necessary to have a faster technique such as Polymerase Chain Reaction (PCR), which corresponds to a very sensitive molecular test. and specific that detects part of the specific genome of the studied pathogen $[2,15,17,18]$.

Basically, the PCR technique consists of the in vitro synthesis of a target DNA sequence in a repetitive manner, thanks to the use of primers or primers (sequence of highly specific oligonucleotides) that recognize sequences that flank the segment of the genome to 
be amplified. This is achieved using Taq polymerase, an enzyme from the bacterium Thermophilus aquaticus that can incorporate free nucleotides at the 3 ' end of the primer, generating copies of the target sequence exponentially, in short time intervals and at high temperatures. It is characterized by its thermostability, high processivity and fidelity $[19,20]$.

Thus, the PCR technique is based on the consecutive repetition of 3 basic steps, which together make up a cycle. First, the target DNA denatures, generating single strands. This process is carried out at temperatures that vary between 90 and $96^{\circ} \mathrm{C}$. The second step is hybridization, or annealing, in which the primers join their complementary fragments on these single strands. The temperature of this stage is specific to each primer. The third and final stage is DNA synthesis, by elongating the primers, thanks to the action of a thermostable polymerase, which, starting from the primers, binds to the target strand and adds nucleotides that will form the complementary strand to it. The result is two double strands of DNA: the original strand and the newly formed strand, which will serve as the target strand or template for the next cycle. This process is repeated between 20 and 40 times [19,20].

At the end of the series of cycles, millions of copies of an area of the original DNA will be generated, which are visualized as bands when performing electrophoresis, in which the DNA is separated according to its molecular weight and its negative electrical charge. The DNA molecules are deposited on a polyacrylamide or agarose gel immersed in a buffer solution, which is subjected to an electric field. The concentration of the agarose determines the speed with which the molecules of interest move, because the smaller the size of the reaction products, the more concentrated the gel must be used, thus, for diagnostic PCR concentrations of 2\% agarose $[19,20-22]$.

\section{Situation in Chile}

In 1992, the presence of CaHV-1 was suggested due to the presentation of perinatal death in a kennel in the Metropolitan Region, since when performing the necropsy of the puppies, petechiae were observed in the kidney and liver and many eosinophilic intranuclear inclusion bodies were observed. A culture of equine kidney cell lines was performed, which showed the characteristic cytopathic effect of herpes virus, however the virus was not isolated [23]. Subsequently, an isolate was detected and biologically characterized national called RP5 [24]. However, since that date no studies had been carried out aimed at the molecular characterization of the isolated virus.
In this context and in parallel to other studies that investigate the presence of the ul37 [25] and glycoprotein B gen [26] of CaHV1 , in this study the detection of a constitutive DNA fragment was implemented of the gC gene, described as the receptor involved in the recognition of herpes virus-infected cells by complement factors [9], thus contributing both to the molecular characterization of the RP5 isolate and to have a molecular alternative for the diagnosis of CaHV-1 in Chile.

\section{Material and Methods}

This report was carried out in the Virology and Microbiology laboratories of the Department of Animal Preventive Medicine of the Faculty of Veterinary and Livestock Sciences of the University of Chile.

\section{Samples}

The virus used in this report was the national isolate RP5 (infected cell culture supernatant) maintained at $-80^{\circ} \mathrm{C}$ in the laboratory of the Animal Virology Unit of the Faculty of Veterinary and Livestock Sciences of the University of Chile. Salmonella enteritidis DNA and Canine Distemper Virus cDNA were included as negative controls. Nuclease-free water (NFW) was used as reagent control.

\section{Polymerase Chain Reaction (PCR).}

\section{Detection of the glycoprotein $C$ gene [10]}

- Primers: The experimental design used in this work contemplated the in-silico design of the primers: PMV1: 5'-AACAAAAATGGCTCCACCAA-3' and PMV2 5'-CCACCCTGGTTTGG TCAATA-5'. These primers were obtained using free access software (online program: OligoPerfect ${ }^{\mathrm{TM}}$ Designer) in which, when entering the official sequence of the $\mathrm{gC}$ gene, it provides both a ranking of primer pairs based on the stability and thermodynamic properties of the union between complementary bases as well as the size of the fragment to be amplified, in this case $202 \mathrm{bp}$, and the melting temperatures (Tm) of each primer (Annex 1). Once designed in silico, their synthesis was entrusted to the company Bioscan.

- Reaction mixture: The reaction mixture consisted of $15 \mathrm{uL}$ of Master Mix 2X PCR, $5 \mathrm{uL}$ of each of the primers $(1 \mu \mathrm{M})$ and 5 $\mu \mathrm{L}$ of the national isolate RP5, obtaining a final volume of 30 $\mathrm{uL}$ in a one tube of $2 \mathrm{~mL}$.

- PCR protocol. Experimental conditions: To determine the optimum alignment temperature of the primers used, a temperature gradient thermocycler (Px2 Thermal Cycler, Thermo Electron Corporation) was used to allows the alignment step to be carried out at a known and individual temperature for each well column of the thermal cycler. 


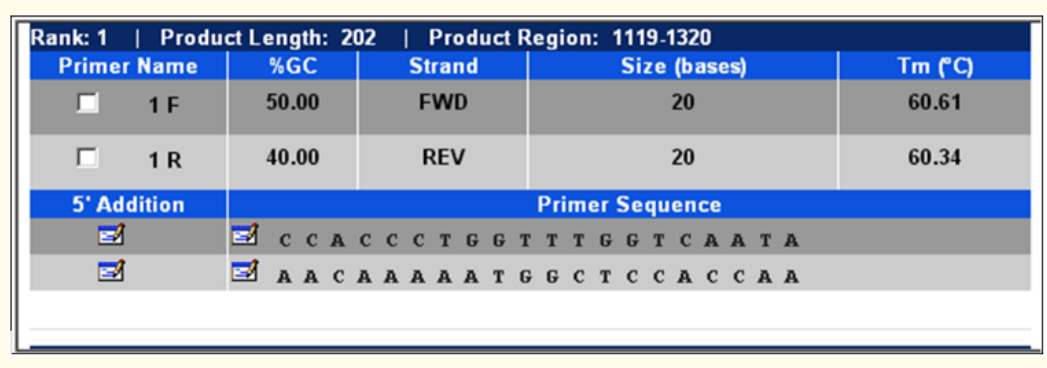

Annex 1: Sequences and Tm of primers and size of the generated amplicon. Online program, OligoPerfect ${ }^{\mathrm{TM}}$ Designer by Life Technologies).

Thus, the PCR protocol used contemplated an initial denaturation at $95^{\circ} \mathrm{C}$ for 2 minutes and then 40 cycles that included denaturation at $95^{\circ} \mathrm{C}$ for 60 seconds, alignment for 60 seconds, and extension at $72^{\circ} \mathrm{C}$ for 60 seconds. Finally, the final elongation at $72^{\circ} \mathrm{C}$ for 10 minutes. The temperature range considered twelve degrees $\left(50^{\circ} \mathrm{C} ; 61^{\circ} \mathrm{C}\right)$.

\section{Detection of amplified products}

To detect the amplified product, electrophoresis was performed on a $2 \%$ agarose gel $\left(\right.$ Winkler $^{\circledR}$ ) in Tris-borate buffer ( 90 mM Trisborate, $10 \mathrm{mM}$ EDTA) as solvent. The PCR product was mixed in a 6:1 ratio with a loading buffer (6X Mass Ruler Loading Dye Solution; Fermentas ${ }^{\circledR}$ ). $6 \mathrm{uL}$ of this mixture were deposited in the respective well of the gel. The protocol used for electrophoresis consisted of $90 \mathrm{~V}$ for 90 minutes. The molecular size marker (MTM) contained DNA fragments between 100 and 1000 base pairs (HyperLadder IV, Bioline ${ }^{\circledR}$ ). After electrophoresis, the gel was incubated in ethidium bromide $\left(0.5 \mathrm{ug} / \mathrm{ml}\right.$; Fermelo $\left.{ }^{\circledR}\right)$ for 30 minutes, then it was observed in an ultraviolet light transilluminator (UVP ${ }^{\circledR}$ Transilluminator) and the resulting image was photographed using a digital camera.

\section{Obtaining nucleotide sequences}

- Amplicon purification: The commercial HI Yield PCR DNA fragments extraction kit (Bioscience ${ }^{\circledR}$ ) was used. $100 \mu \mathrm{l}$ of the reaction mixture was transferred to a microcentrifuge tube, five volumes of Buffer DF were added, and vortexed. The mixture was applied to a DF column assembled in a 2 $\mathrm{ml}$ plastic tube. It was centrifuged at $10,000 \times \mathrm{g}$ for one minute at room temperature and residual liquid was removed. Then $600 \mu \mathrm{l}$ of wash buffer diluted in absolute ethanol was added and centrifuged at $10,000 \times \mathrm{g}$ for one minute at room temperature. Residual fluid was removed and replaced the column in the tube. The empty column was centrifuged for two minutes at room temperature. It was placed in a $1.5 \mathrm{ml}$ plastic tube and $30 \mu \mathrm{l}$ of nuclease-free water was added. It was incubated for two minutes at room temperature. Subsequently, it was centrifuged at $10,000 \times \mathrm{g}$ for two minutes to elute the DNA.

- $\quad$ Sequencing: 3 samples of DNA obtained (in duplicated) in an approximate concentration of $50 \mathrm{ng} / \mu \mathrm{l}$, were sent to the company Genytec. The sequences obtained were aligned using the free online program Clustal $\Omega$ [27] to obtain a consensus sequence, which was entered as data into the free online software program BLAST ${ }^{\circledR}$ (Basic Local Alignment Search Tool) to determine the percentage of nucleotide identity (PIN) with respect to nucleotide sequences available in the Genbank database (Anexx 3).

\section{Results}

Detection of the HCV glycoprotein C gene in samples of the RP5 isolate.

Visualizing the $2 \%$ agarose gel under UV light, it was possible to observe a DNA band of around $200 \mathrm{bp}$ in all the different annealing temperatures, being the clearest in lanes 4 and 5 , corresponding to the annealing temperatures of 55 and $56^{\circ} \mathrm{C}$ respectively, as shown in figure 1.

Determination of the nucleotide identity of the fragment displayed in lane 4

The amplicons obtained were sent to the company Genytec, to carry out their sequencing (Annex 2). Using the Clustal $\Omega$ program, the following consensus sequence was obtained: 


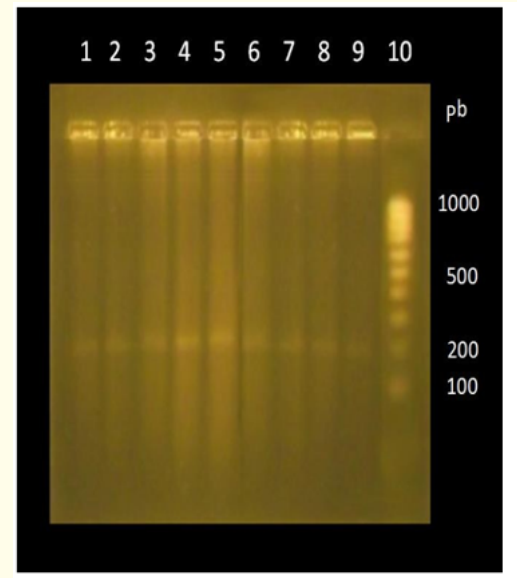

\begin{tabular}{|l|l|}
\hline Lane & Alignment Temperature $\left({ }^{\circ} \mathrm{C}\right)$ \\
\hline 1 & 52 \\
\hline 2 & 53 \\
\hline 3 & 54 \\
\hline 4 & 55 \\
\hline 5 & 56 \\
\hline 6 & 57 \\
\hline 7 & 58 \\
\hline 8 & 59 \\
\hline 9 & 60 \\
\hline 10 & MSM \\
\hline MSM: Molecular Size Marker (100-1000 bp) \\
\hline
\end{tabular}

Figure 1: Electrophoresis (Agarose, 2\%). Temperature gradient PCR $\left(52^{\circ} \mathrm{C} \rightarrow 60^{\circ} \mathrm{C}\right)$.

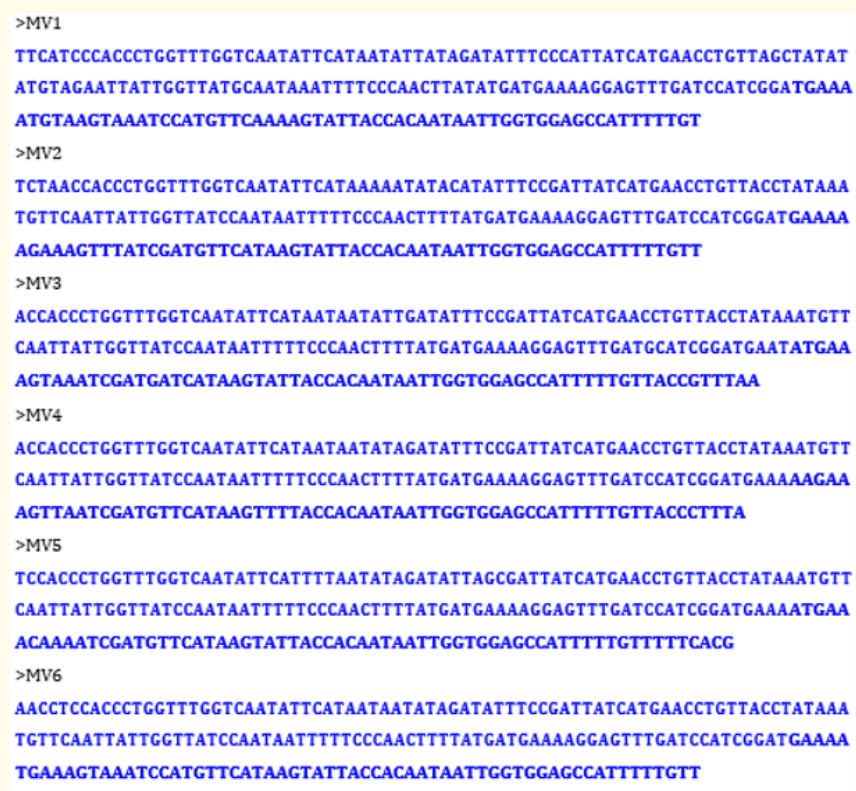

Annex 2: Sequences obtained from the amplicons sent to Genytec.

$>$ MDVV ACCACCCTGGTTTGGTCAATATTCATAATAATATAGATATTTCCGATTATCATGAACCTGTTACCTATAATGTTCAATTATTGGTTATCCAATAATTTTTCCCAACTTTTATGATGAAAAGGAGTTTGATCCATCGGATGAAAATGAAAGTAAATCGATGTTCATAAGTATTACCACAATAATTGGTGGAGCCATTTTTGTT
When entering the MDVV sequence to the BLAST ${ }^{\circledR}$ program, a Nucleotide Identity Percentage (NIP) around 95\% was obtained with respect to the sequences of all those present in the Genbank database that presented similarity with the MDVV sequence, both sequences correspond to the CaHV-1 gC gene (Annexes 3 and 4). 


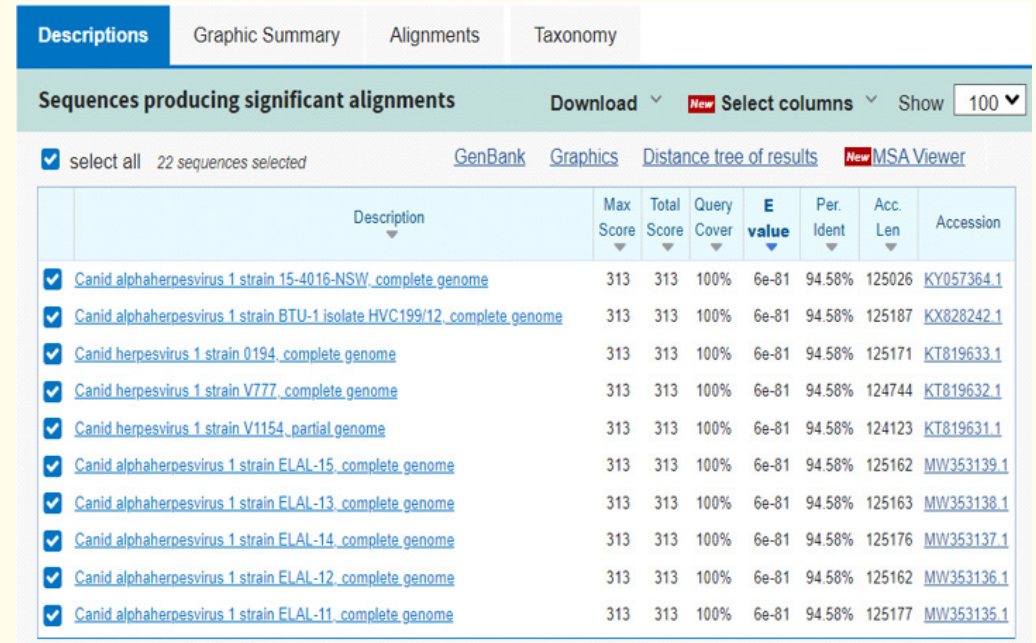

Annex 3: NIP of MDVV sequence according to the BLAST® program.

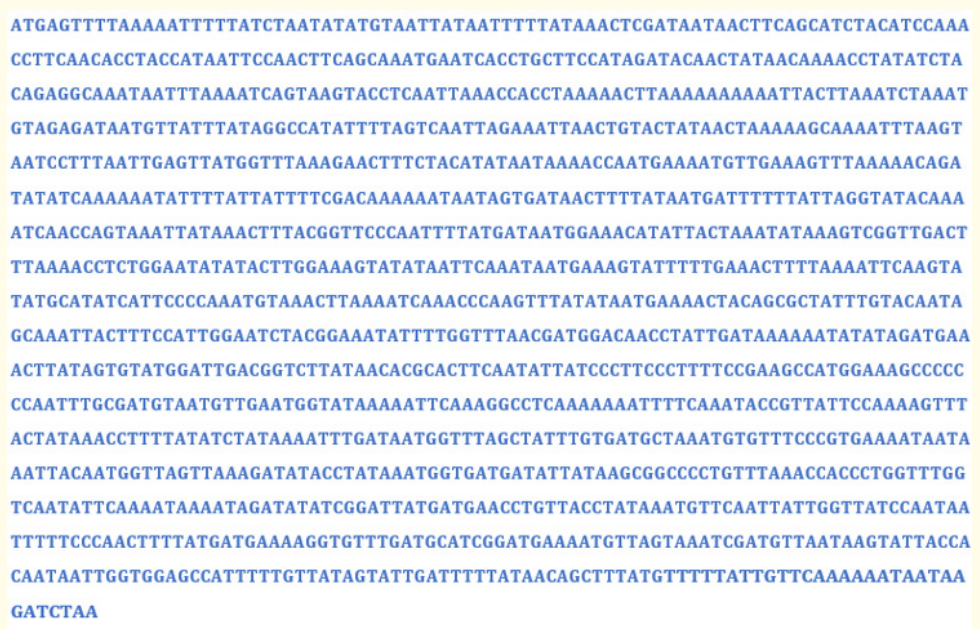

Annex 4: Sequence of the CaHV-1 gC gene (Reubel., et al. 2002). 1380 bp.

\section{Discussion and Conclusion}

There are several methods of approach to the diagnosis of CaHV-1-1 infection, highlighting both the clinical examination in live animals as well as necropsy and histopathological studies in dead animals. However, these methods are not definitive, as they only suggest the presence of the virus. Thus, the definitive diagnosis continues to be viral isolation, which takes about a month.

If these diagnostic methods are compared with a PCR protocol, it is clear that the latter has considerable advantages: greater specificity, because it detects the presence of a specific DNA fragment belonging to a specific gene of the pathogen in question, greater sensitivity, since that in each cycle an exponential increase of the product to be detected is generated and finally, the faster obtaining of results [3,15,17-20].

In this context, currently in FAVET others methods have been implemented that involve the conventional PCR technique for the diagnosis of CaHV-1: the detection of the UL37, TK and gB gene. These methods, together with the one presented here -which involved the design of primers in silico, the determination of the annealing temperature and the visualization of a DNA fragment of 
around $200 \mathrm{bp}$ - are oriented in the search for a definitive method of molecular diagnosis of CaHV-1 useful in Small Animal Medicine.

In view of the results obtained, it can be established that the design of the in silico primers (PMV1 and PMV2) turned out to be a successful strategy, together with the determination of the alignment temperature of 55을 $\mathrm{C}$ using the temperature gradient thermocycler. This was confirmed by the sharp visualization of a single DNA fragment of about $200 \mathrm{bp}$ on the $2 \%$ agarose gel.

Additionally, the use of the BLAST ${ }^{\circledR}$ online program allowed us to corroborate -through a high NIP value- that the $200 \mathrm{bp}$ DNA fragment obtained is constitutive of the CaHV-1 gC gene (annexes 3 and 4 ), a conserved gene encoding for glycoprotein C of CaHV-1, recognized for its ability to stimulate the cellular immune response in the host, being important in the activation of the cellular response, mediated by $\mathrm{T}$ lymphocytes [4,28-30].

However, although the implemented method allowed the molecular detection of CaHV-1 and complements the molecular study of the native RP5 isolate, it is still not possible to determine which of the PCR protocols would be the one of choice for the definitive diagnosis.

By finally having an early detection of CaHV-1 by PCR, the diagnosis of an infection would be implemented that is aimed at solving a current two-pronged problem: one related to animal welfare or affective, and the other economic. In the first case, the high mortality observed in puppies under four weeks could be avoided, as well as -through timely diagnosis- avoiding the crossing of infected animals. Regarding the second aspect, an infected animal in a farm translates into large future losses, due to abortions and neonatal deaths. Furthermore, as infected individuals remain carriers for life, affected breeders must be definitively removed from the hatchery.

In conclusion, the PCR protocol using the glycoprotein $\mathrm{C}$ gene as detection target can be used as a diagnostic method for CaHV1. However, to define the optimal molecular method, it is recommended to carry out a short-term study comparing the sensitivity of PCR for each of the CaHV-1 genes detected. Additionally, this study contributed to the genomic characterization of the national isolate RP5 by detecting the $\mathrm{gC}$ gene of the canine herpes virus in its genome.

\section{Bibliography}

1. ICTV. "International Committee on Taxonomy of Viruses". Virus Taxonomy (2020).

2. Carter GR., et al. Herpesviridae. In: "A Concise Review of Veterinary Virology" G.R. Carter, D.J. Wise and E.F. Flores (Eds.) Publisher: International Veterinary Information Service. Ithaca, New York, USA (2006).

3. Murphy FA., et al. "Veterinary virology. $3^{\text {rd }}$ ed. Ed. Academic Press. London, Inglaterra (1999).

4. Papageorgiou KV., et al. "Genome Sequence of Canine Herpesvirus”. PLoS ONE 11.5 (2016): e0156015.

5. Madigan MT., et al. "Brock. Biología de los microorganismos". 10a ed. Ed. Pearson. Madrid, España (2003): 1011.

6. Liu F and Zhou ZH. "Comparative virion structures of human herpesviruses. In: Arvin A, Campadelli-Fiume G, Mocarski E, et al., editors. Human Herpesviruses: Biology, Therapy, and Immunoprophylaxis. Cambridge: Cambridge University Press (2007).

7. Boehmer P and Lehman I. "Herpes simplex virus DNA replication". Annual Review of Biochemistry 66 (1997): 347-384.

8. Norval M. "Virus-cell interactions". Medical Microbiology (2012): 82-96.

9. Friedman $\mathrm{H}$., et al. "Glycoprotein $\mathrm{C}$ of herpes simplex virus 1 acts as a receptor for the $\mathrm{C} 3 \mathrm{~b}$ complement component on infected cells". Nature 390 (1984): 633-635.

10. Reubel GH., et al. "Nucleotide sequence of glycoprotein genes $\mathrm{B}, \mathrm{C}, \mathrm{D}, \mathrm{G}, \mathrm{H}$ and $\mathrm{I}$, the thymidine kinase and protein kinase genes and gene homologue UL24 of an Australian isolate of canine herpesvirus". Virus Genes 25.2 (2002): 195-200.

11. Xuan X., et al. "Analysis of canine herpesvirus gB, gC and gD by a recombinant vaccinia virus". Archives of Virology 142.5 (1997): 1003-1010.

12. Limbach K., et al. "Nucleotide sequence of the genes encoding the canine herpesvirus gB, gC and gD homologues". Journal of General Virology 7.8 (1994): 2029-2039. 
13. Tyack S., et al. "Nucleotide sequence of canine herpesvirus homologues of herpes simplex virus type 1 US2, US3, glycoproteins I and E, US8.5 and US9 genes". DNA Sequencing (1997): 365-368.

14. Cargnelutti J., et al. "Outbreaks of canid herpesvirus 1 disease in puppies in southern Brazil". Pesquisa Veterinaria Brasileira 35.06 (2015).

15. Dumon C and Mimouni P. "Mortinatalidad asociada an enfermedades infecciosas en la cría canina: brucelosis, herpesvirosis, micoplasmosis. In: Enciclopedia Veterinaria, Lafont A.; Durieux F. Ed. Elsevier. E-RE 2250 (2005): 1-7.

16. Rota A., et al. "Seroprevalence of Canine Herpesvirus-1 in Breeding Dogs with or Without Vaccination in Northwest Italy". Animals 10.7 (2020): 1116.

17. Erles K., et al. "Longitudinal study of viruses Associated with Canine Infectious Respiratory Disease". Journal of Clinical Microbiology 42.10 (2004): 4524-4529.

18. Ronsse V., et al. "Canine herpesvirus-1 (CHV-1): clinical, serological and virological patterns in breeding colonies". Theriogenology 64.1 (2005): 61-74.

19. Mullis K and Faloona F. "Specific synthesis of DNA in vitro via a polymerase- catalyzed chain reaction". Methods of Enzymology 155 (1987): 335-350.

20. Ghannam MG and Varacallo M. "Biochemistry, Polymerase Chain Reaction. In: StatPearls Internet. Treasure Island (FL): StatPearls Publishing (2021).

21. Danchin A and Yuek KY. "Bacterial genomics in the study of Virulence". In SUSSMAN Molecular Medical Microbiology. Barcelona. España. Academic Press (2002): 341-353.

22. Pennington T. "Electrophoretic typing. In SUSSMAN Molecular medical microbiology". Barcelona. España. Academic Press (2002): 535-547.

23. Larenas J., et al. "Primeros antecedentes en Chile de infección por herpes canino con mortalidad neonatal: Mevepa" 1 (1992): 13-16.

24. Navarro C., et al. "Virus herpes canino en Chile: Propiedades biológicas". Archivos de Medicina Veterinaria 37.2 (2005): 133137.
25. Fuentes A., et al. "Detection of ul37 gene from Canine Herpes Virus by Polymerase Chain Reaction". IJMRGE 53.3-4 (2022): 227-237.

26. Carrasco L., et al. "Detection of the canine herpes virus glycoprotein B gene via Polymerase Chain Reaction. Open Access Research Journal of Multidisciplinary Studies (2022).

27. Clustal Omega.“Multiple Sequence Alignment” (2021).

28. Mikloska $\mathrm{Z}$ and Cunningham AL. "Herpes simplex virus type 1 glycoproteins $\mathrm{gB}, \mathrm{gC}$ and $\mathrm{gD}$ are major targets for CD4 Tlymphocyte cytotoxicity". Journal of General Virology 79.pt2 (1989): 353-361.

29. Arsenakis M., et al. "Expression and regulationof glycoprotein C gene of herpes simplex virus 1". Journal of General Virology 58.2 (1986): 367-376.

30. Rosenthal KL., et al. "Cells Expressing Herpes Simplex Virus Glycoprotein gC but Not gB, gD, or gE Are Recognized by Murine Virus Specific Cytotoxic T Lymphocytes". Journal of General Virology 61.8 (1987): 2438-2447.

\section{Assets from publication with us}

- Prompt Acknowledgement after receiving the article

- Thorough Double blinded peer review

- Rapid Publication

- Issue of Publication Certificate

- High visibility of your Published work

Website: www.actascientific.com/

Submit Article: www.actascientific.com/submission.php

Email us: editor@actascientific.com

Contact us: +919182824667 